\title{
User's Guide to the Water-Analysis Screening Tool (WAST): A Tool for Assessing Available Water Resources in Relation to Aquatic-Resources Uses
}

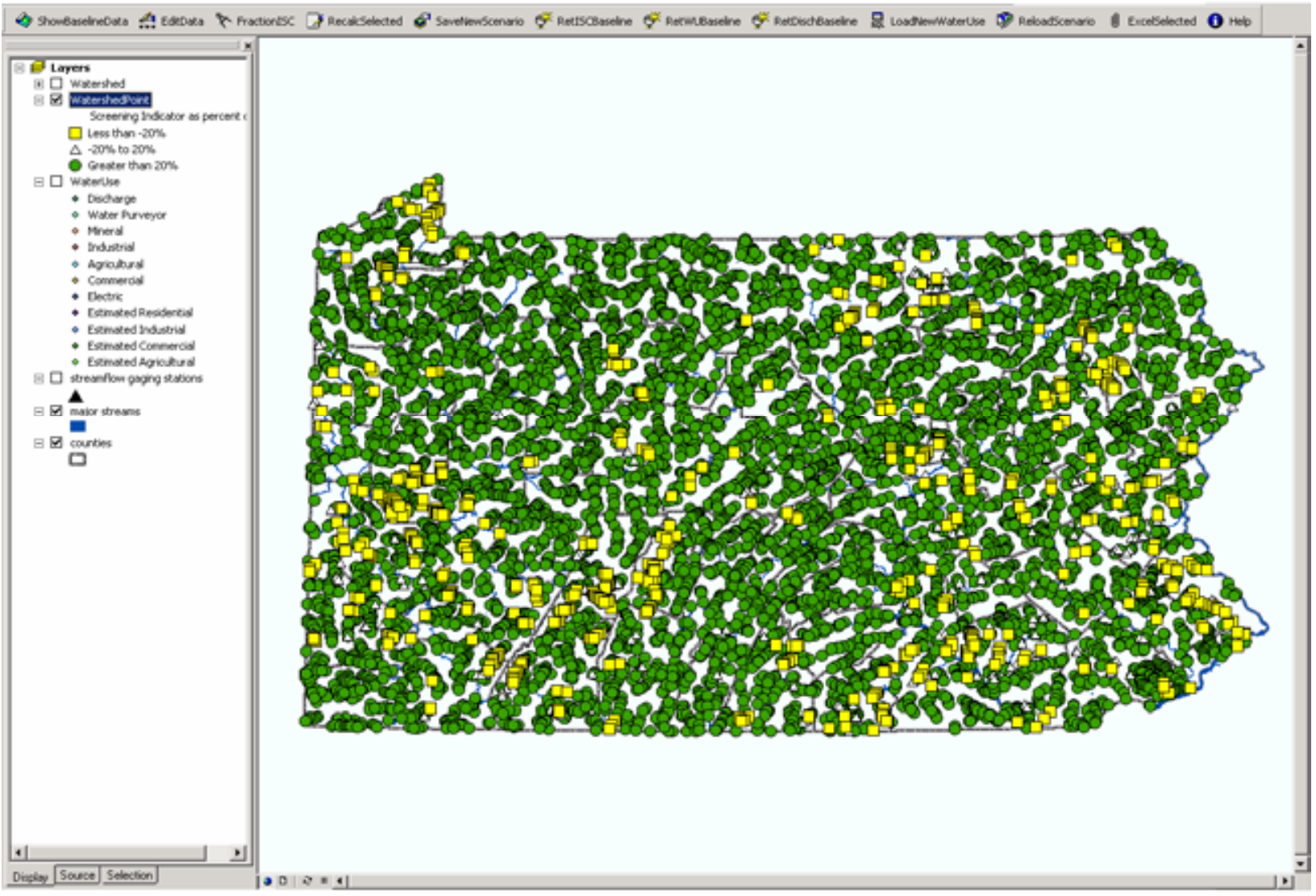

Open-File Report 2008-1242

U.S. Department of the Interior

U.S. Geological Survey 
Cover. Opening screen of the water-analysis screening tool. 


\section{User's Guide to the Water-Analysis Screening Tool (WAST): A Tool for Assessing Available Water Resources in Relation to Aquatic-Resource Uses}

By Marla H. Stuckey and James L. Kiesler

Prepared in cooperation with the Pennsylvania Department of Environmental Protection

Open-File Report 2008-1242 


\title{
U.S. Department of the Interior DIRK KEMPTHORNE, Secretary
}

\author{
U.S. Geological Survey \\ Mark D. Myers, Director
}

U.S. Geological Survey, Reston, Virginia: 2008

For product and ordering information:

World Wide Web: http://www.usgs.gov/pubprod

Telephone: 1-888-ASK-USGS

For more information on the USGS--the Federal source for science about the Earth, its natural and living resources, natural hazards, and the environment:

World Wide Web: http://www.usgs.gov

Telephone: 1-888-ASK-USGS

Any use of trade, product, or firm names is for descriptive purposes only and does not imply endorsement by the U.S. Government.

Although this report is in the public domain, permission must be secured from the individual copyright owners to reproduce any copyrighted materials contained within this report.

Suggested citation:

Stuckey, M.H., and Kiesler, J.L., 2008, User's guide to the water-analysis screening tool (WAST)—A tool for assessing available water resources in relation to aquatic-resource uses: U.S. Geological Survey Open-File Report 2008-1242, $19 \mathrm{p}$. 


\section{Contents}

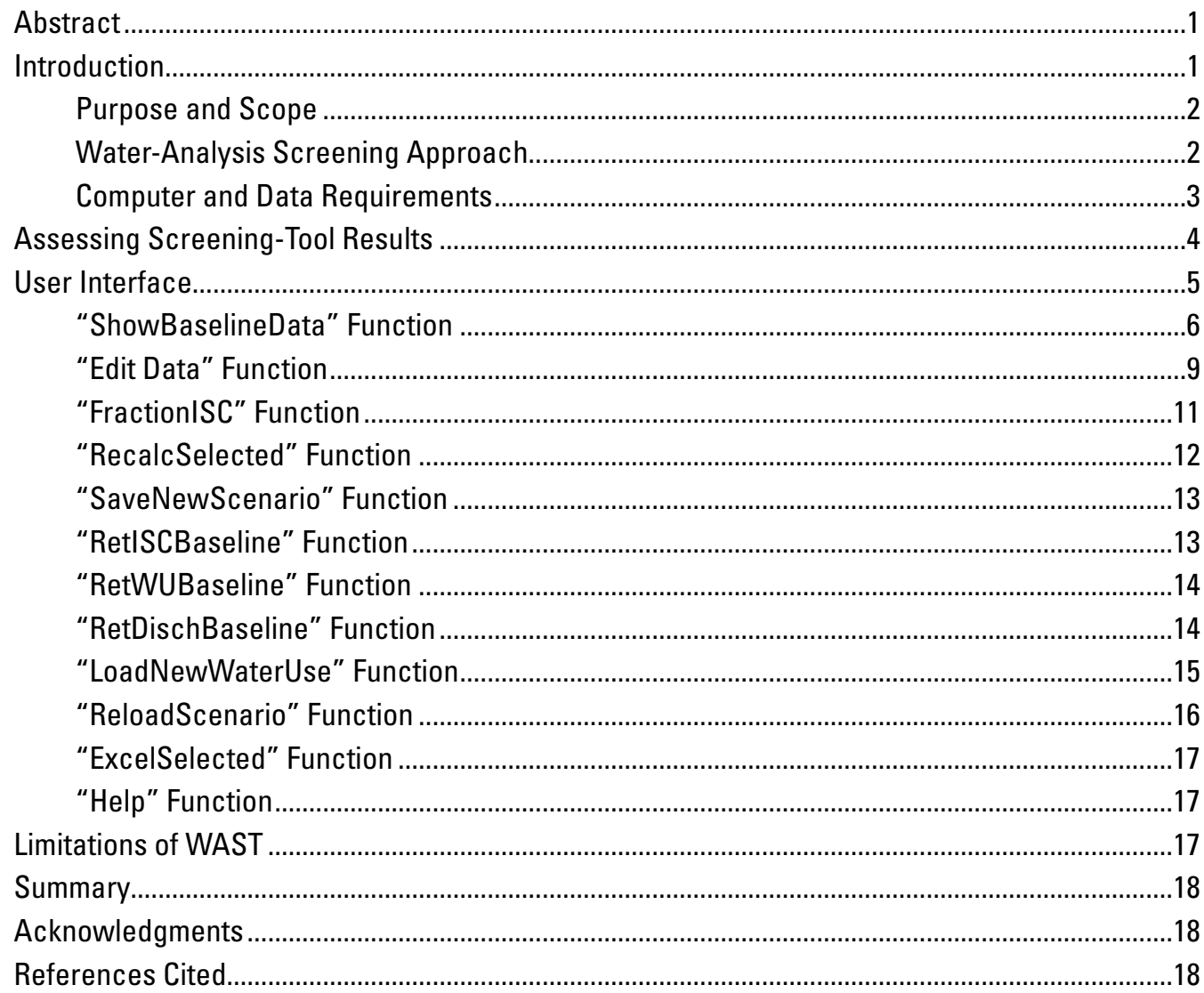

Appendix 1. Water-Analysis Screening Tool Code

separate file

Appendix 2. Reference Libraries Needed to Run the Water-Analysis Screening Tool

separate file

Appendix 3. Data Dictionaries for the Water-Analysis Screening Tool Databases...... separate file

Appendix 4. Example Databases... separate file

Appendix 5. Guidelines for Resolving Problems Encountered While Running the Water-Analysis Screening Tool separate file 


\section{Figures}

1. Geodatabase structure of water-analysis screening tool

2. Relation betweeen pour point and watersheds used in the water-analysis screening tool

3. Opening screen of water-analysis screening tool ..............................................................

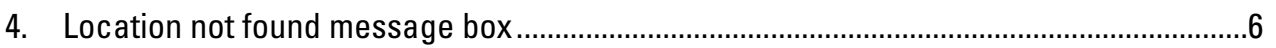

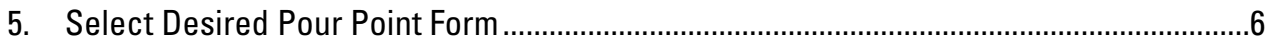

6. Show Basin Data Form and basin delineation ..................................................................

7. Potential regulation statement on Show Basin Data Form ..............................................

8. Edit Pour Point Data Form and basin delineation...........................................................

9. Edit Pour Point Data Form showing fractionate of 7010 ................................................10

10. Edit Pour Point Data Form showing water-use edits .....................................................11

11. Adjusting percentage of 7-day, 10-year low flow using the FractionISC function ..........11

12. Message box using the RecalcSelected function ..........................................................12

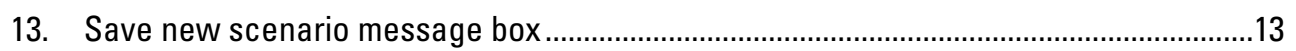

14. Return initial screening criteria to baseline message box ..............................................13

15. Return water use to baseline message box......................................................................14

16. Return discharges to baseline message box........................................................................14

17. Water-use reference date message box...............................................................................16

18. Invalid water-use reference date message box ................................................................16

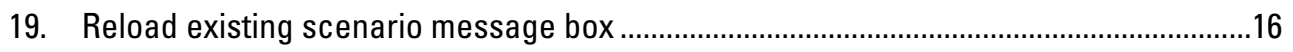

\section{Tables}

1. Steps required to run "LoadNewWaterUse" function. 


\section{Conversion Factors and Acronyms}

\begin{tabular}{|c|c|c|}
\hline Multiply & By & To obtain \\
\hline \multicolumn{3}{|c|}{ Area } \\
\hline square mile $\left(\mathrm{mi}^{2}\right)$ & 2.590 & square kilometer $\left(\mathrm{km}^{2}\right)$ \\
\hline \multicolumn{3}{|c|}{ Flow rate } \\
\hline million gallons per day (Mgal/d) & 0.04381 & cubic meter per second $\left(\mathrm{m}^{3} / \mathrm{s}\right)$ \\
\hline
\end{tabular}

\section{Acronyms}

$\begin{array}{ll}\text { 7Q10 } & \text { 7-day, 10-year low flow } \\ \text { CWPA } & \text { Critical Water-Planning Area } \\ \text { GIS } & \text { Geographic Information System } \\ \text { ISC } & \text { Initial screening criteria } \\ \text { NHD } & \text { National Hydrography Dataset } \\ \text { NW } & \text { Net withdrawals } \\ \text { SI } & \text { Screening indicator } \\ \text { SIP } & \text { Screening indicator as a percentage } \\ \text { WAST } & \text { Water-analysis screening tool }\end{array}$




\title{
User's Guide to the Water-Analysis Screening Tool (WAST): A Tool for Assessing Available Water Resources in Relation to Aquatic-Resource Uses
}

\author{
By Marla H. Stuckey and James L. Kiesler
}

\begin{abstract}
A water-analysis screening tool (WAST) was developed by the U.S. Geological Survey, in partnership with the Pennsylvania Department of Environmental Protection, to provide an initial screening of areas in the state where potential problems may exist related to the availability of water resources to meet current and future water-use demands. The tool compares water-use information to an initial screening criteria of the 7-day, 10-year low-flow statistic (7Q10) resulting in a screening indicator for influences of net withdrawals (withdrawals minus discharges) on aquatic-resource uses. This report is intended to serve as a guide for using the screening tool.

The WAST can display general basin characteristics, water-use information, and screening-indicator information for over 10,000 watersheds in the state. The tool includes 12 primary functions that allow the user to display watershed information, edit water-use and water-supply information, observe effects downstream from edited water-use information, reset edited values to baseline, load new water-use information, save and retrieve scenarios, and save output as a Microsoft Excel spreadsheet.
\end{abstract}

\section{Introduction}

The Water Resources Planning Act, Act 220 of 2002 (Water Resources Planning Act of 2002 (P.L. 1776, No. 220)), requires the Pennsylvania Department of Environmental Protection (PaDEP) to update the State Water Plan by 2008 and every 5 years thereafter. As part of this update, areas of the state need to be identified where potential problems may exist related to the availability of water resources to meet current and future water-use demands. These potential problem areas are termed Critical Water-Planning Areas (CWPAs). The first step in the identification of CWPAs is an initial screening of the state utilizing watersupply and water-use information to determine areas that need further examination. After this initial screening, the PaDEP plans to evaluate areas of potential concern using more detailed data, including reservoir effects and other mitigation factors.

A water-analysis screening tool (WAST) initially conceived by the PaDEP was developed in partnership with the PaDEP by the U.S. Geological Survey (USGS) to provide assistance in the identification of CWPAs. The WAST was developed for use in Pennsylvania to assist the PaDEP in the identification of CWPAs; however, the application could be used outside the state or for different purposes. The watershed-based geospatial tool is used in the initial screening of the state to evaluate potential influences of net withdrawals on aquatic-resource uses. Aquatic-resource uses have been influential in the selection of initial criteria used in the WAST. The tool compares water-use information to initial screening criteria (ISC), resulting in a screening indicator (SI) for influences of net withdrawals on aquatic-resource uses for over 10,000 watersheds in the state. The ISC is a percentage of the 7-day, 10-year low-flow statistic $\left(7 \mathrm{Q} 10^{1}\right)$. Net withdrawals $(\mathrm{NW})$ are the total withdrawals minus the total discharges in a watershed. The term "discharge," for the purposes of this report, is defined by the amount of water returned to the hydrologic system by the water user or facility. Water-use and water-supply information can be edited within the WAST to further refine the inputs for a particular watershed to more closely replicate actual conditions. For the purposes of this report, the term "water supply" is defined by the amount of natural flow in a stream prior to any upstream withdrawals or discharges.

\footnotetext{
${ }^{1}$ The 7-day, 10-year low flow is the discharge at the 10-year recurrence interval taken from a frequency curve of annual values of the lowest mean discharge for 7 consecutive days (the 7-day low flow).
} 


\section{Purpose and Scope}

This report provides instructions for using the WAST developed by the USGS Pennsylvania Water Science Center (PAWSC) in partnership with the PaDEP. This report is intended to serve as a user's guide for the WAST. This report also presents background information about the ISC developed for Pennsylvania and how to interpret results obtained from the WAST. Database structure and computer requirements are presented. The program code is included in appendix 1.

\section{Water-Analysis Screening Approach}

An overview of the water-analysis screening approach is presented here to help the WAST user develop an understanding of functions described in the following sections. A more complete explanation of the initial screening methodology used in the State Water Plan update is provided in Stuckey (2008). The ISC were established in cooperation with the CWPA Subcommittee for the purpose of identifying potential CWPAs. The CWPA Subcommittee is a subcommittee of the Statewide Water Resources Committee that establishes guidelines and policies to be used as part of the State Water Plan update. The ISC were adopted using aquatic-resource uses as the determining factor (Pennsylvania Department of Environmental Protection, 2006). The ISC is 50 percent of the $7 \mathrm{Q} 10$ flow for all streams except those designated as Class $\mathrm{A}^{2}$ trout streams in areas of carbonate bedrock, where 30 percent of the 7Q10 flow is used. The 7Q10 used to determine the ISC is computed by use of regional regression equations developed by the USGS (Stuckey, 2006).

The WAST has two primary inputs: net withdrawals (NW), which are total withdrawals minus total discharges, and the water supply, which is determined by the value of the ISC. Assuming the following three situations for the initial screening, 1) surface-water and ground-water resources are one resource, 2) total withdrawals include both surface-water and ground-water withdrawals, and 3) withdrawals are unmitigated (without considering any conservation releases or pass-by requirements), then the potential influences of NW on aquatic-resource uses are defined as the SI. A basic water-balance equation is used in the determination of SI, as shown below.

$$
S I=I S C-N W
$$

Where:

SI is a screening indicator of the potential influence of NW on aquatic-resource uses for a watershed, in million gallons per day;

ISC is the initial screening criteria for a watershed as determined by a percentage of $7 \mathrm{Q} 10$, in million gallons per day; and

$N W \quad$ is the net withdrawal for a watershed as determined by total withdrawal minus total discharge, in million gallons per day.

SI is calculated at points across the state representing watersheds generally larger than $15 \mathrm{mi}^{2}$. These points are termed "pour points" and refer to the point on a stream that is the outlet of a watershed. To correlate and compare SI between watersheds with different drainage-area sizes and different volumes of natural flow, a dimensionless screening indicator (SIP) is computed. SIP is determined using equation 2:

$$
S I P=[(I S C-N W) / I S C] \times 100
$$

Where:

SIP is the screening indicator of the potential influence of NW on aquatic-resource uses for a watershed, as a percentage;

ISC is the initial screening criteria for a watershed as determined by a percentage of $7 \mathrm{Q} 10$, in million gallons per day; and

$N W \quad$ is the net withdrawal for a watershed as determined by total withdrawal minus total discharge, in million gallons per day.

\footnotetext{
${ }^{2}$ Class A stream reaches are designated by the Pennsylvania Fish and Boat Commission as streams that "support a population of naturally produced trout of sufficient size and abundance to support a long-term and rewarding sport fishery" (Pennsylvania Fish and Boat Commission, 2007).
} 


\section{Computer and Data Requirements}

The WAST is built on a Microsoft Windows XP Service Pack 2 platform and uses ArcGIS ArcMap 9.2 (ESRI, 2007). No additional ArcGIS extensions are needed to run the WAST; however, ArcCatalog is used to compact the geodatabases. Computer requirements needed to run ArcMap 9.2 are listed on the ESRI website at http://support.esri.com/. A complete list of reference libraries recommended to run the WAST is provided in appendix 2. To verify the libraries are selected, in the ArcMap session, select Tools; Macros; Visual Basic Editor. A Visual Basic window will open, and select Tools; References to check selected references.

The WAST utilizes a geodatabase structure to store, retrieve, and display data. Three geodatabases are needed to run the WAST (fig. 1), and data dictionaries for the geodatabases are listed in appendix 3. The geodatabases (Basins.mdb, WaterUsePoints.mdb, and Edits.mdb) must not be renamed. The geodatabase Basins.mdb contains the points and delineations for all watersheds included in the tool. The geodatabase WaterUsePoints.mdb contains the water-use information. The geodatabase Edits.mdb contains any edits made to either the water-use or water-supply information that relate to a saved scenario.

The WAST and all three supporting geodatabases are contained in one directory. This directory can get large, up to 5 gigabytes. It is important to compact the geodatabases regularly, especially the Basins.mdb, to keep the size below about 2 megabytes, the maximum allowed for an individual database inherent with Microsoft Access. It is recommended that a copy of all databases and the WAST be kept in a separate directory.

The WAST was developed for use in Pennsylvania to assist the PaDEP in the identification of CWPAs; however, the application could be used outside the state or for different purposes. The databases described above and in appendix 3 would need to be populated with data developed for the project area. The watershed points and delineations used in the Pennsylvania application were determined using techniques developed by the USGS using the 1:24,000 scale National Hydrography Dataset (NHD) (U.S. Geological Survey, 2004). The ISC can be altered to a project's needs; most streamflow statistics could be used in the WAST. Example databases and the WAST are included in appendix 4.

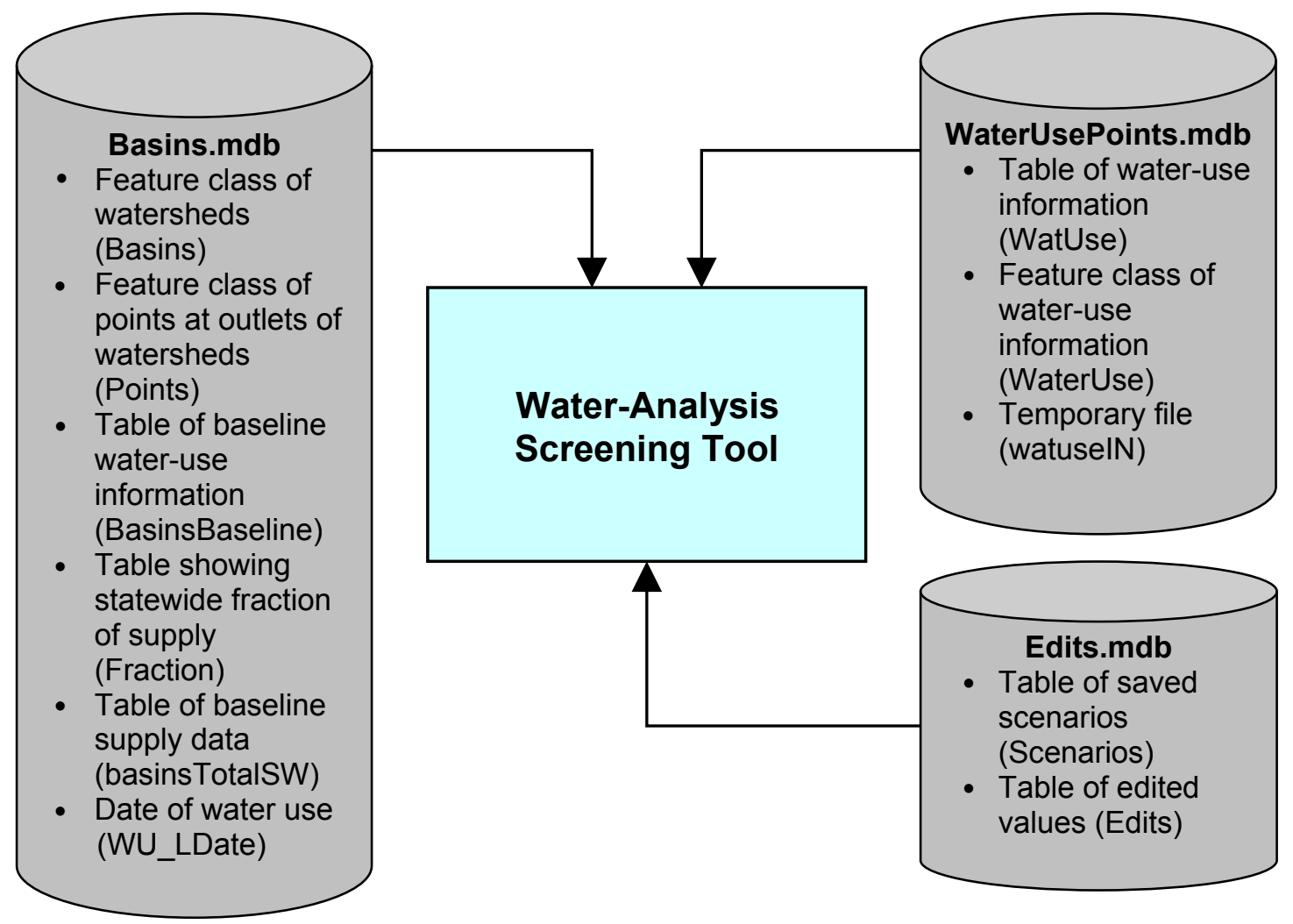

Figure 1. Geodatabase structure of water-analysis screening tool. The three geodatabses, Basins.mdb, WaterUsePoints.mdb, and Edits.mdb, are shown with their components. 


\section{Assessing Screening-Tool Results}

The SIP is displayed in the WAST as ranges of colors for pour points representing the outlets of watersheds. These pour points represent the entire watershed upstream of the point (fig. 2). From figure 2, watershed A is the most upstream basin; watershed B contains watershed A and the subbasin between watersheds A and B; watershed C contains both watersheds A and $\mathrm{B}$, as well as the subbasin between watersheds B and C. Basin characteristics, ISC, water use, SI, and SIP are determined for each watershed and related to the respective pour point through a corresponding unique identifier.

A circular, green pour point is used to designate watersheds with SIP greater than 20 percent. Green pour points indicate watersheds with a low potential for conflicts with aquatic-resource uses. These areas are likely to have adequate water to meet the water-use demands and are less likely to be designated as a CWPA than other watersheds. A triangular, white pour point is used to designate watersheds with SIP between -20 percent and 20 percent. White pour points indicate watersheds with a potential for conflicts with aquatic-resource uses. These areas cannot conclusively be labeled as having a high or low potential for conflicts. A square, yellow pour point is used to designate watersheds with SIP less than -20 percent. Yellow pour points indicate watersheds with a high potential for conflicts with aquatic-resource uses. These are areas where water-use demands are exceeding the ISC and are more likely to be designated as a CWPA than other watersheds. The SIP categories and their described potential for water-use demand conflicts were established in cooperation with the PaDEP.

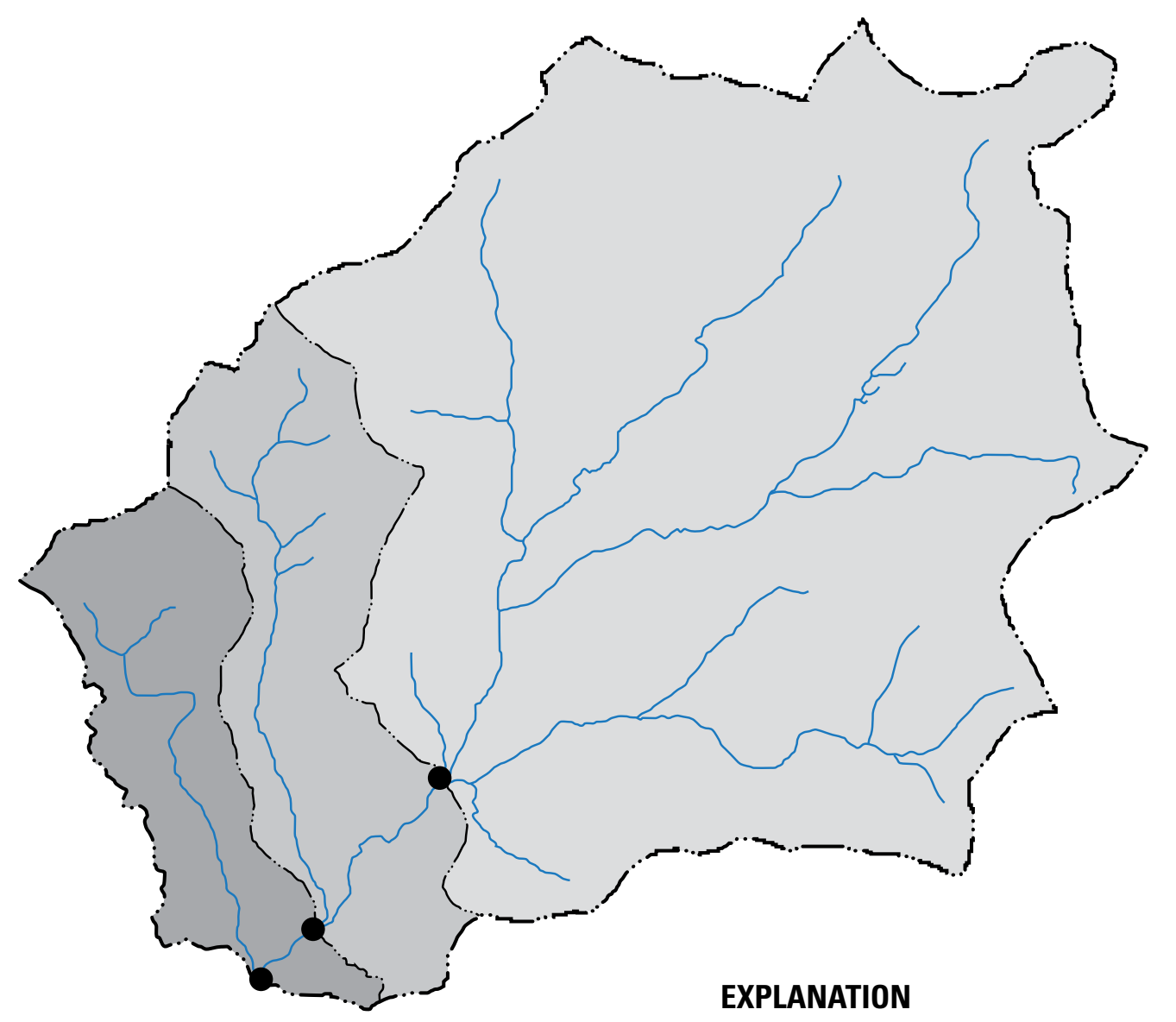

Watershed A

Watershed B

Watershed C

- Pour point

Figure 2. Relation betweeen pour point and watersheds used in the water-analysis screening tool. 


\section{User Interface}

The WAST is opened using ArcMap. After opening WAST in an ArcMap session, three primary map layers shown in the table of contents are needed to run the tool (fig. 3). These layers do not need to be in any certain order but must be named accordingly. The three layers are WatershedPoint from the Points table in the Basins.mdb; WaterUse, from the WaterUse table in the WaterUsePoints.mdb; and Watershed, from the Basins table in Basins.mdb. A join is established between WatershedPoint.DrainID and Watershed.HydroID. The join must not be removed or changed. The Watershed layer should be turned off. The user can add other supporting layers to the WAST, such as counties, streams, streamflow-gaging stations, roads, and municipalities, as needed. However, the Watershed and WatershedPoint layers must be loaded before any other layers.

The WatershedPoint layer should be the only selectable layer. To check that no other layers are selected, select the ArcMap menu Selection; Set Selectable Layers; WatershedPoint should be the only layer indicated. If other layers need to be temporarily selected for identification purposes, do not run any WAST functions while they are selected. If any new layers are added, remove them from the list of selectable layers.

The WAST toolbar includes buttons for 12 primary functions, described in the following sections (fig. 3). The functions are ShowBaselineData, EditData, FractionISC, RecalcSelected, SaveNewScenario, RetISCBaseline, RetWUBaseline, RetDischBaseline, LoadNewWaterUse, ReloadScenario, ExcelSelected, and Help. To assist the user with possible problems encountered while running the WAST, a general trouble-shooting guide is presented in appendix 5.

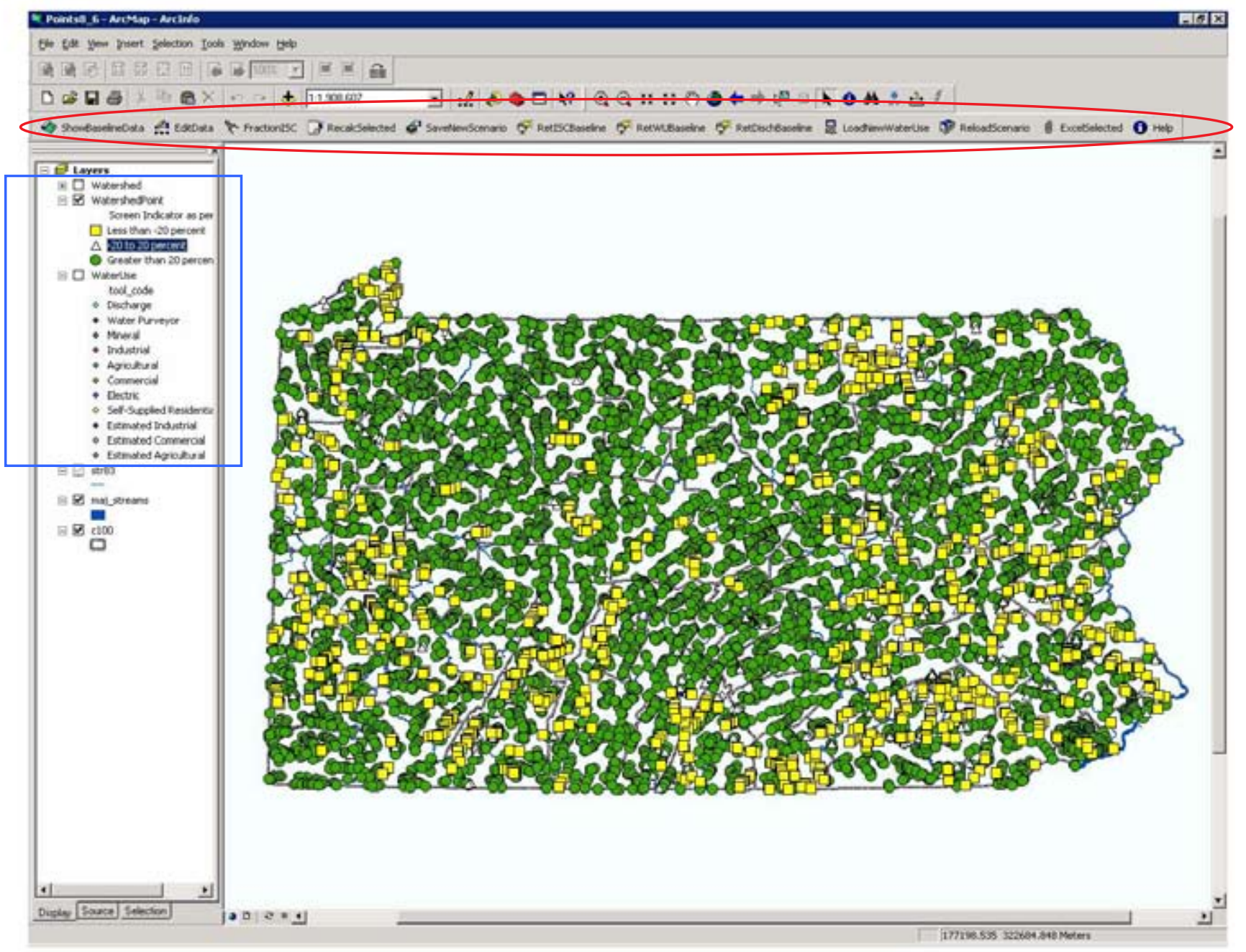

Figure 3. Opening screen of water-analysis screening tool. Red oval points out the tool bar for the water-analysis screening tool. Blue square points out the three primary map layers needed to run the tool. (Simulated portrayal. May not represent actual conditions.) 


\section{“ShowBaselineData" Function}

The purpose of this function is to display the baseline values of the data elements used to describe the SIP and selected watershed characteristics at a selected pour point. The baseline value of the ISC is 100 percent of the 7Q10 and baseline water use are the unedited values loaded into the WAST. To use this function, zoom to the area of interest within the ArcMap document. Then click on the "ShowBaselineData" button on the toolbar followed by the pour point of interest. The pour points may be labeled in the WAST using Basins.HydroID, which is the unique identifier associated with each pour point, to assist in the selection of pour points. A message box as shown in figure 4 will be displayed if a point is selected without zooming in to an area. If this message box appears, select ok, and zoom closer to the point of interest. If there are two or more pour points close together, a Select Desired Pour Point Form will appear with all the nearby points listed (fig. 5). Select one of the points by clicking on the number of the point followed by the "Use Selected Point" button, and the tool functions will follow. The delineation of the basin defined by the pour point will be drawn in the color representing the SIP and the Show Basin Data Form will be displayed (fig. 6).

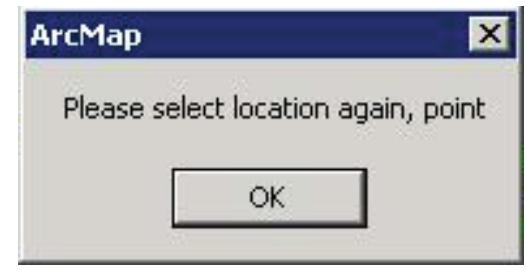

Figure 4. Location not found message box.

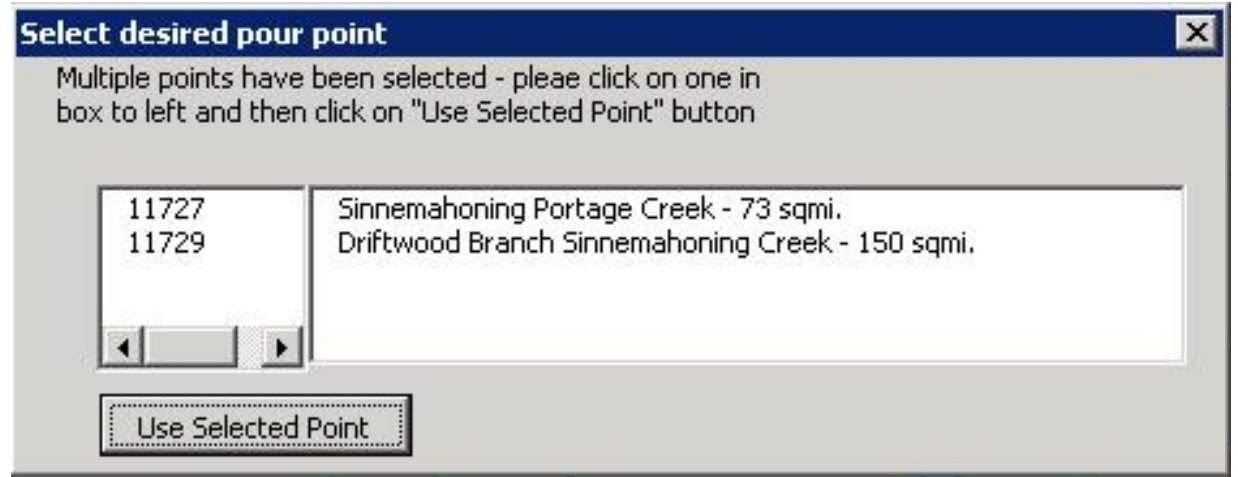

Figure 5. Select Desired Pour Point Form. 


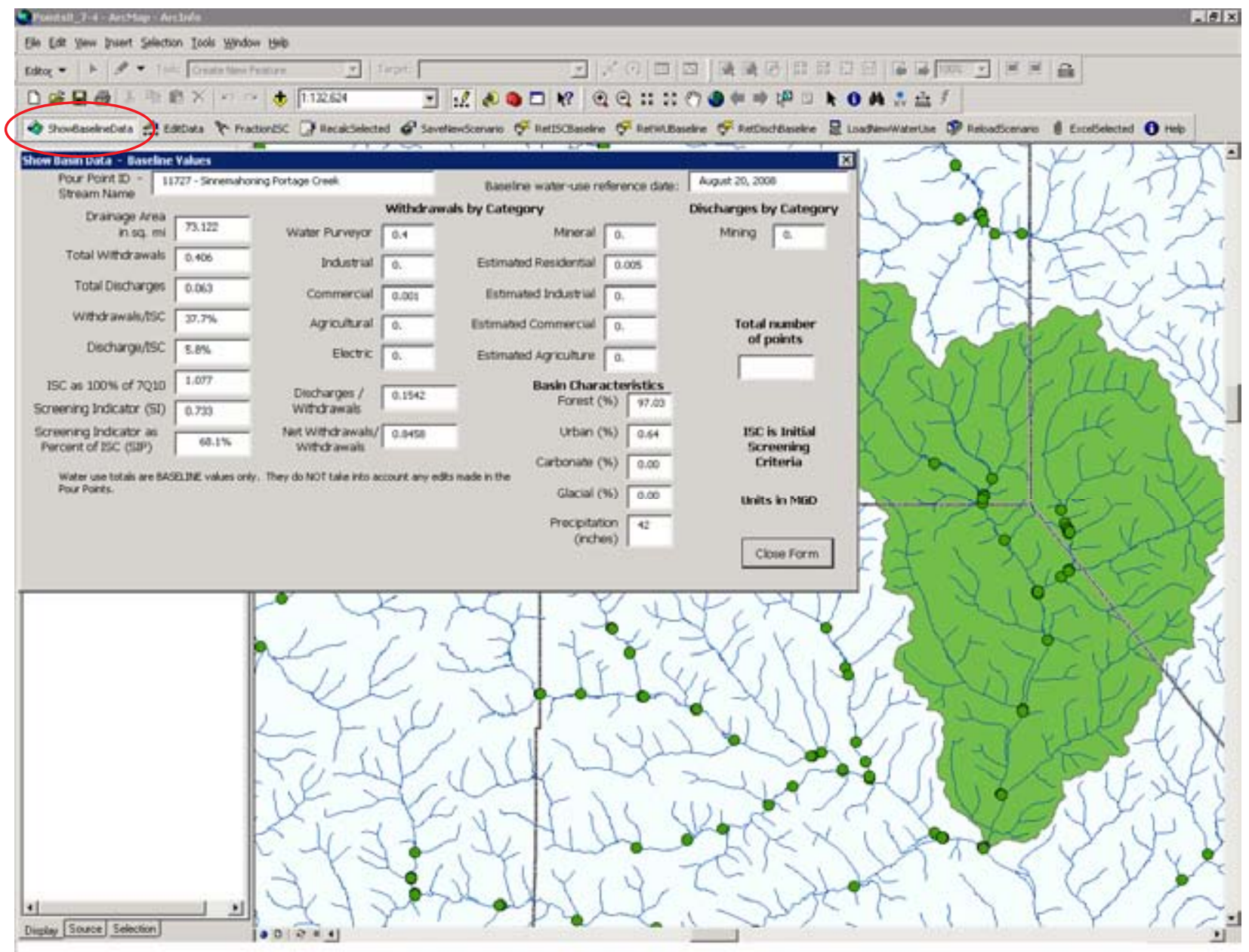

Figure 6. Show Basin Data Form and basin delineation. Red oval points out the "Show Baseline Data" button.

The Show Basin Data Form displays the baseline values for the selected pour point. If any data have been edited, the edits are not reflected in this form. Information about the watershed is displayed and is described below. The date of the water-use information is shown in the upper right of the form. To close this form, click on the "Close Form" button in the lower right hand corner of the form.

\section{General Watershed Information:}

Pour Point ID/ Stream Name is the unique identifier of the point selected and stream name, if available;

Baseline water-use reference date is the reference date of the water-use information;

Drainage Area is the drainage area of the watershed, in square miles;

Total Withdrawals is the sum of all withdrawals in the watershed, in million gallons per day;

Total Discharges is the sum of all discharges in the watershed, in million gallons per day;

Withdrawals/ISC is the ratio of total withdrawals to the ISC, as a percent;

Discharge/ISC is the ratio of total discharges to the ISC, as a percent;

ISC as $100 \%$ of $7 Q 10$ is 100 percent of the $7 \mathrm{Q} 10$ as determined from Stuckey (2006), in million gallons per day;

Screening Indicator $(S I)$ is the screening indicator, in million gallons per day;

Screening Indicator as percent of ISC (SIP) is the screening indicator, as a percent;

Discharges/Withdrawals is the ratio of total discharges to total withdrawals, dimensionless;

Net Withdrawals/Withdrawals is the ratio of NW to total withdrawals, dimensionless;

Total number of points is the number of pour points, including the one selected, that are contained in the selected watershed. 


\section{Water-Use Information:}

Withdrawals by categories are displayed for water purveyor, industrial, commercial, agricultural, electric, mineral, estimated residential, estimated industrial, estimated commercial, and estimated agriculture. Discharge by category is displayed for mining. All water-use information was determined using methods described by Stuckey (2008). Water-use totals are in million gallons per day.

\section{Basin Characteristics:}

Basin characteristics are displayed including mean annual precipitation, in inches, and percentage of basin containing forested area, urban area, carbonate geology, and past glacial activity. Basin characteristics were determined as described by Stuckey (2006).

If the watershed contains a dam listed by the National Inventory of Dams within the watershed delineation, a message in blue appears on the bottom of the form (fig. 7) that states, "This basin has one or more dams (as defined by the National Inventory of Dams) within the drainage area. Flow statistics may be affected by upstream regulation." Users are encouraged to investigate the type of dam contained in the watershed and whether or not it may affect the results of the WAST before continuing. If a streamflow-gaging station with flow subject to regulation has been identified near the pour point and is within 0.3 to 3 times the drainage area of the point, then the 7Q10 statistic computed from gaging-station data is transferred to the pour point. If a transferred 7Q10 statistic has been computed, it is shown at the bottom of the Show Basin Data Form in blue under the message regarding a dam (fig. 7). This statistic is for informational purposes only and is not used in any calculations pertaining to the pour point such as SI or SIP.

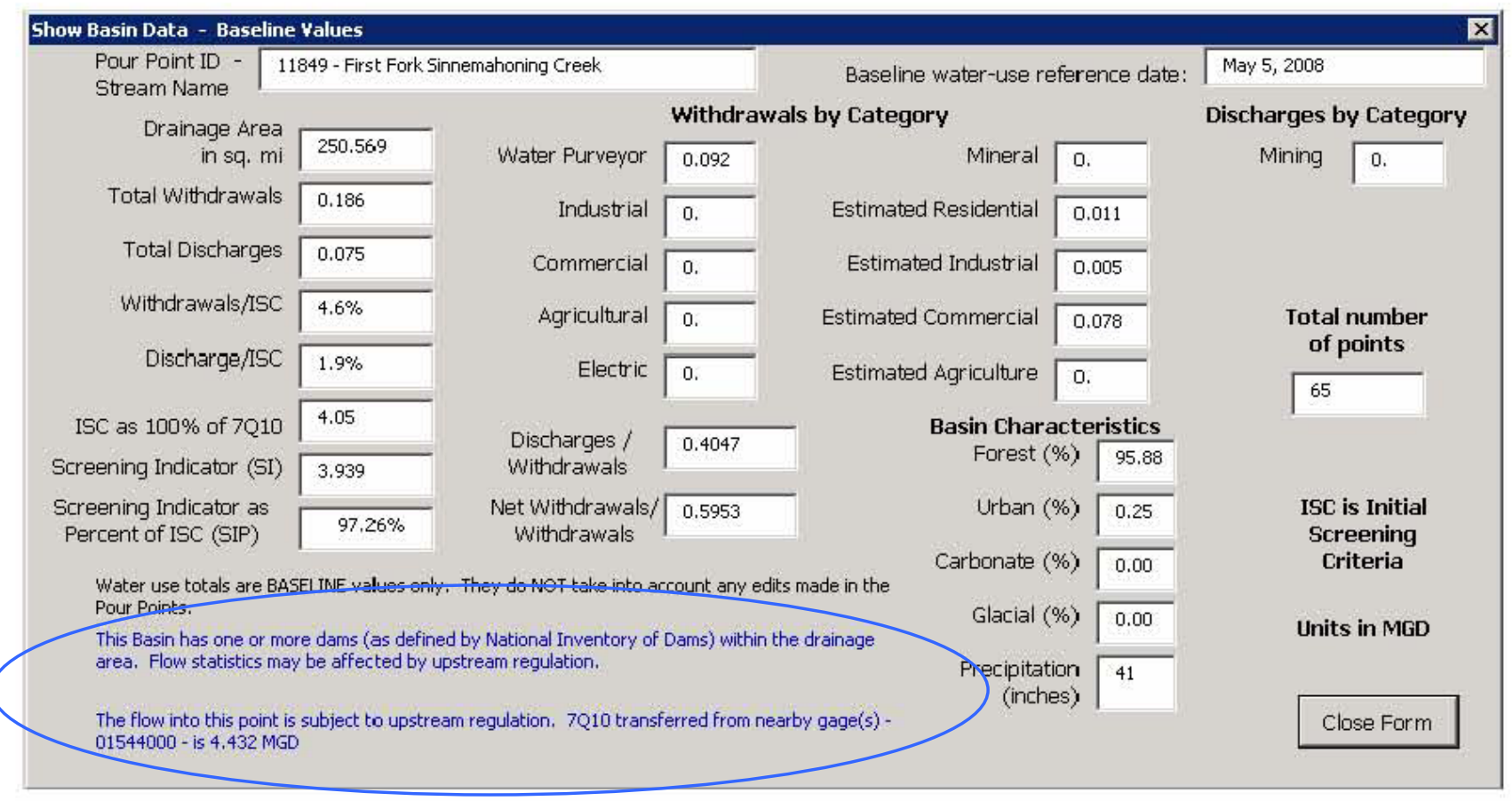

Figure 7. Potential regulation statement on Show Basin Data Form. Blue oval points out the potential regulation statement. 


\section{“Edit Data" Function}

The purpose of this function is to display the current values of the data elements used to describe the SIP at a selected pour point. In addition to displaying the current values, the form can be used to modify the data values. To use this function, zoom to the area of interest within the ArcMap document. Click on the "EditData" button found on the toolbar followed by the pour point of interest. If a point is selected without zooming to an appropriate level, or two or more points are close together, a message box or form as shown in figures 4 and 5, respectively, will be displayed. The delineation of the basin defined by the pour point will be drawn in the color representing the SIP and two forms will be displayed (fig. 8). Any pour points within the delineated watershed that have been previously edited will be highlighted with a larger than normal symbol size. The first form is the Show Basin Data Form that was discussed previously. The second form is the Edit Pour Point Data Form that displays the current values of the data elements defining the pour point. Data values including ISC, withdrawals, and discharges can be modified on this form and updated screening indicators will be displayed.

To edit the ISC, click within the "ISC as 7Q10" box on the Edit Pour Point Data Form and type the new value. The SI and SIP fields will automatically be updated. The ISC also can be modified by changing the fraction of the 7Q10. The baseline value for ISC is 100 percent of the 7Q10. The 7Q10 can be fractionated by entering in a percentage value from 1 to 32,000 in

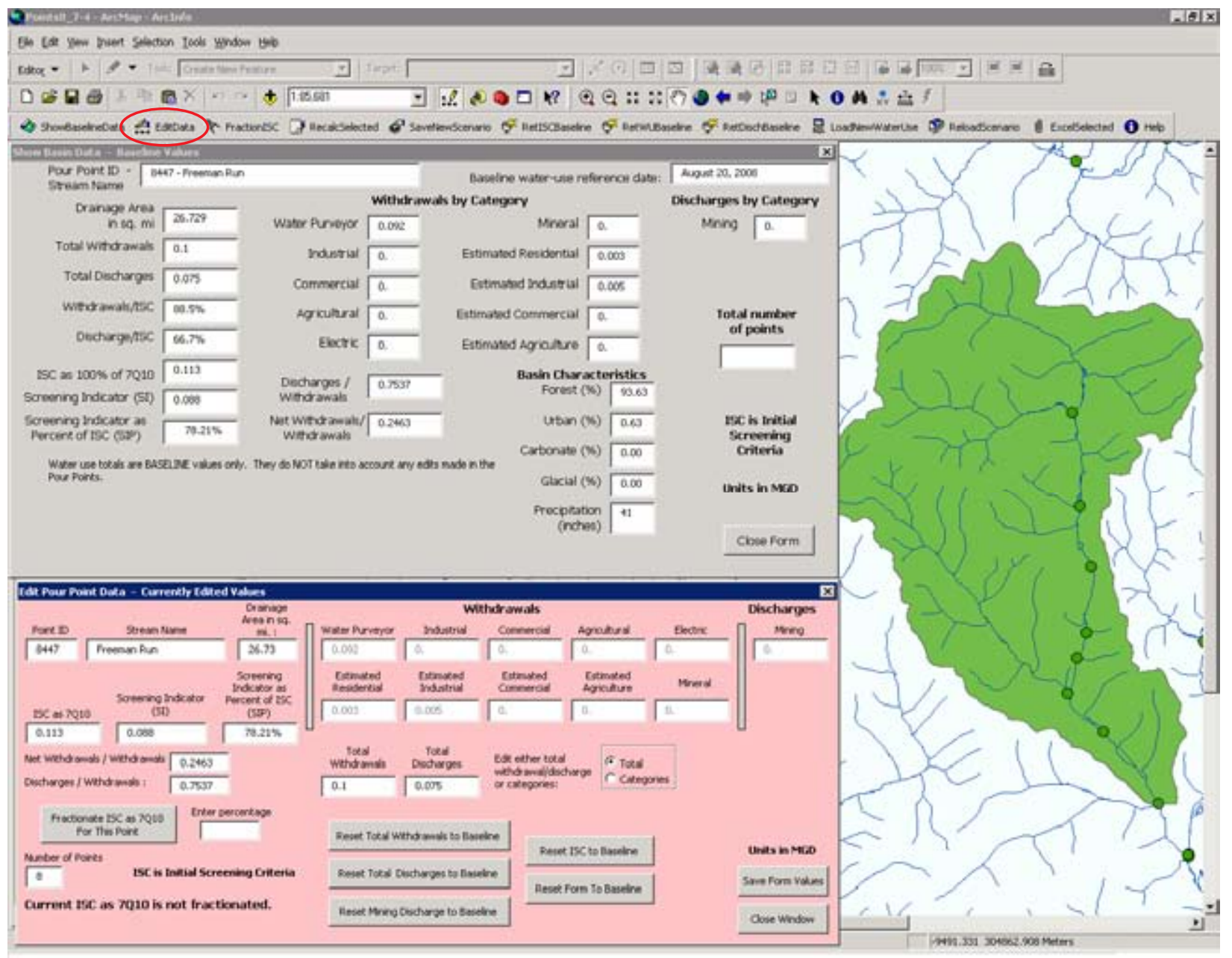

Figure 8. Edit Pour Point Data Form and basin delineation. Red oval points out the "Edit Data"button. 
the "Enter percentage" box and clicking on the "Fractionate ISC as 7Q10 For This Point" button (fig. 9). This percentage is calculated from the baseline value regardless of any previous fraction adjustments. The SI and SIP fields will be automatically updated. A message appearing on the bottom of the form alerts the user that the 7Q10 has been fractionated (fig. 9).

When using the "EditData" function to edit withdrawals or discharges, either the total or categories can be modified. The default is to edit by totals; to edit by categories, the toggle button must be changed to reflect categories (fig. 10). If the "Total" button is chosen, only the "Total Withdrawal" or "Total Discharges" data values can be modified. If the "Categories" button is chosen, "Total Withdrawal" or "Total Discharges" is calculated as the sum of all withdrawal or discharge categories. One note, both the total and the categories fields can be edited and a warning appears to alert user that the other has already been modified. If both fields are modified, the value for the total withdrawal will not be modified when a demand category is modified. After the new value(s) have been entered, the SI and SIP fields will automatically be updated.

Data fields in the Edit Pour Point Data Form that have been modified by the user have a yellow background. Data fields that have been modified during an automated process, such as through the "RecalcSelected" function, have a cyan background. The exception to this is the "Total Withdrawals" field. The value in this field will have a yellow background color only if the "Total Withdrawal" value has been modified by the user through a direct change. If the "Total Withdrawal" value differs from the baseline because one or more of the demand categories have been modified, the "Total Withdrawal" background color will remain white. Any pour points within the delineated basin that have been previously edited will be highlighted with a larger than normal symbol size.

At the bottom of the Edit Pour Point Data Form are five buttons that return edited data fields to baseline values. Total withdrawals, total discharges, mining discharges, ISC, or the entire form can be reset to baseline values by selecting one of the buttons. The "Reset Form to Baseline" button returns any data fields that have been edited back to baseline. To save edits, click on the "Save Form Values" button in the lower right hand corner of the Edit Pour Point Data Form. To close this form, click on the "Close Form" button in the lower right hand corner of the form. Both forms will close. Closing the form does not save edited values.

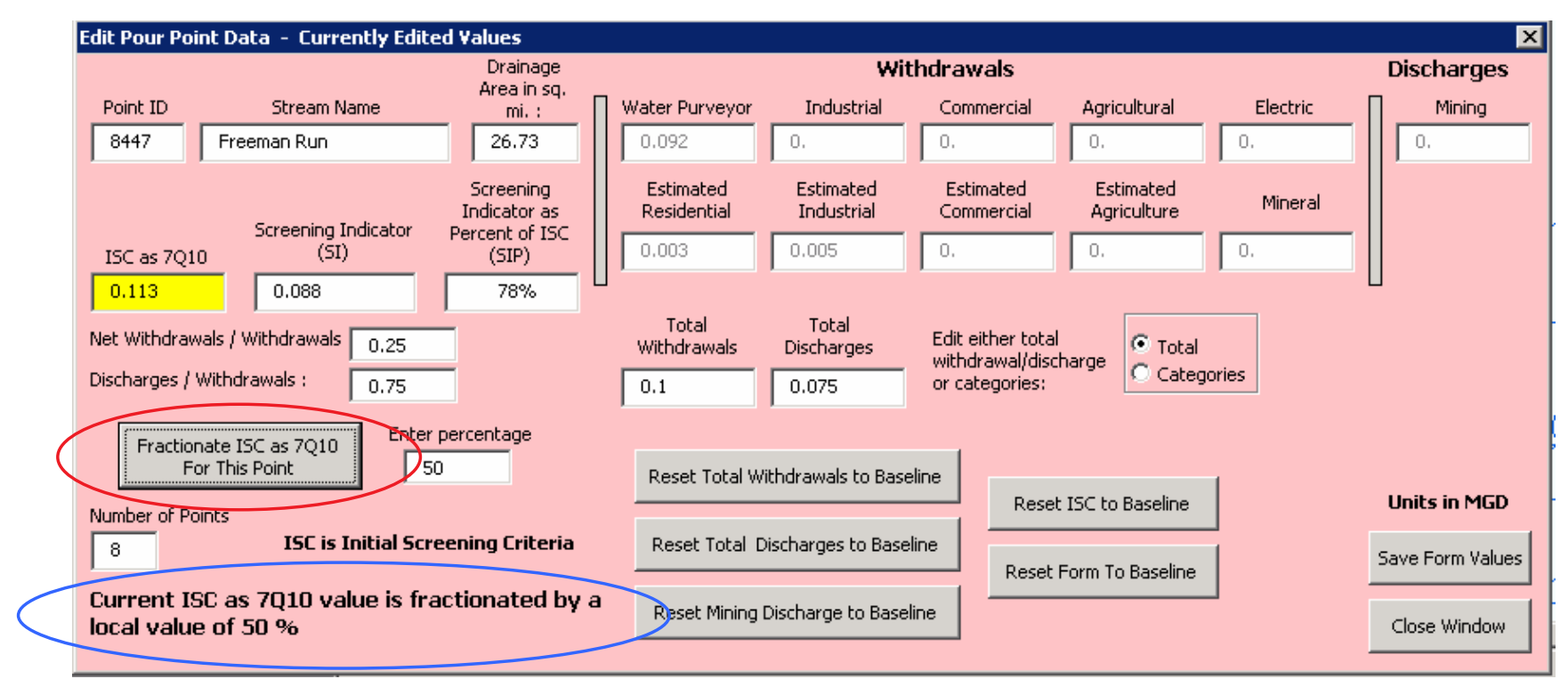

Figure 9. Edit Pour Point Data Form showing fractionate of 7010. Red oval points out the "Fractionate ISC as 7010 For This Pour Point" button. Blue oval points out the status of ISC fractionation. 


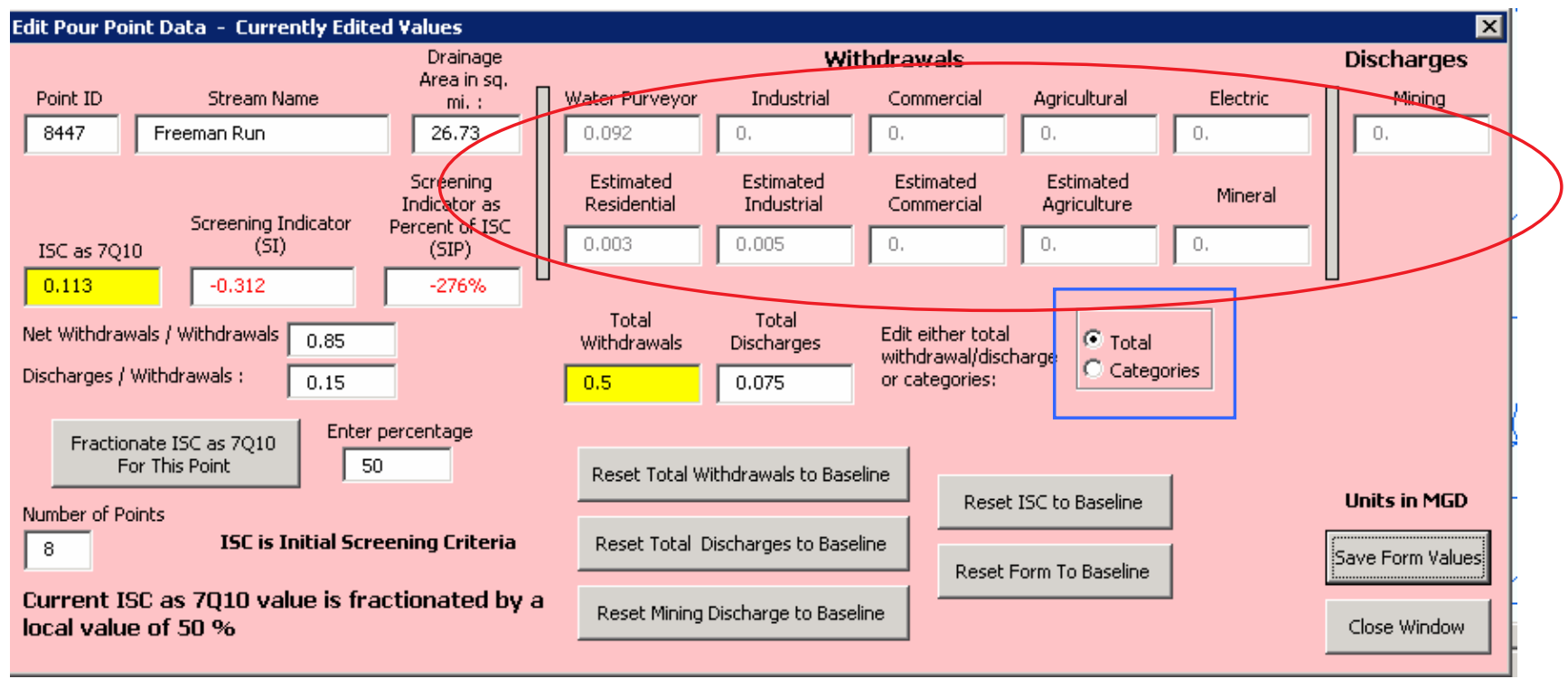

Figure 10. Edit Pour Point Data Form showing water-use edits. Blue square points out the toggle button to edit data. Red oval points out the categorical water use.

\section{“FractionISC" Function}

The purpose of this function is to universally apply a percentage to the 7Q10 values for all pour points. The "FractionISC" button replaces any single-point fractionations or previously applied universal fractionations by using the baseline 7Q10. To use this function, click on the "FractionISC" button on the toolbar, and a message box will be displayed (fig. 11). A percentage of the 7Q10 may be entered in the box between 1 percent and 32,000 percent. The maximum 32,000 value is the maximum number allowed for a real single-precision number. An error is shown if a percentage outside of this range is entered. Values less than 100 will reduce the ISC as a percentage of the 7Q10, and values greater than 100 will increase the ISC. Refresh the map after using the "FractionISC" function to display updated colors at pour points.

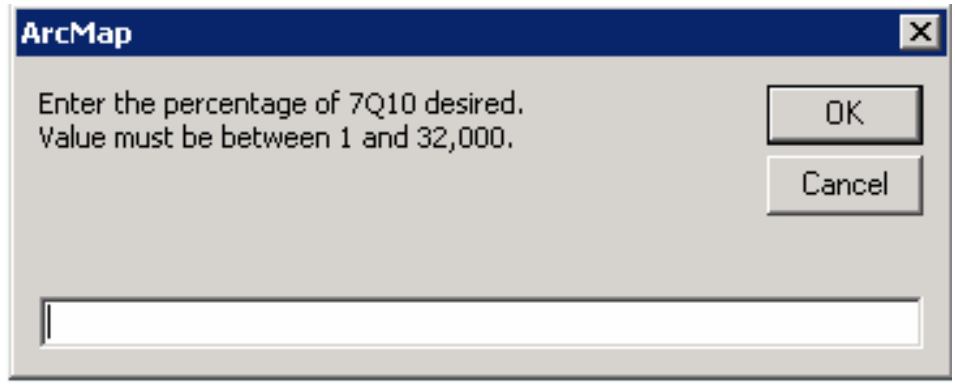

Figure 11. Adjusting percentage of 7-day, 10-year low flow using the FractionISC function. 


\section{User's Guide to the Water-Analysis Screening Tool}

Current percentage value is maintained in the Fraction table of Basins.mdb. The last applied fraction function, either by using the "FractionISC" function or the fraction 7Q10 feature on the Edit Pour Point Data Form for a single point, is the percentage used. This allows users, for example, to universally apply 50 percent of the $7 \mathrm{Q} 10$ to the state and modify points individually to a different percentage. To return all points to 100 percent of the 7Q10, including the points edited through use of the Edit Pour Point Data Form, 100 percent is entered using the "FractionISC" function.

\section{“RecalcSelected" Function}

The purpose of this function is to adjust the "Total Withdrawal" and "Total Discharge" values and recalculate the SI and SIP for pour points downstream of previously edited pour points. The function gathers all the pour points within the basins defined by each of the selected pour points. For each selected pour point, the "Total Withdrawal" and "Total Discharge" values are adjusted for edits made to the pour points within the basin defined by the selected pour point. This function allows the user to observe downstream effects from edits to water-use information in upstream watersheds. Water-use values updated using this function will have a cyan background when viewed on the Edit Pour Point Data Form.

To use this function, first use the ArcGIS feature selection tool ( recalculation. The Select by Location feature in ArcGIS does not work with the "RecalcSelected" function. The WatershedPoints layer should be the only selectable layer. Hold the "Shift" key down to select multiple points or click and hold down while dragging the box over multiple points. There is no maximum or minimum number of pour points that can be selected and processed. The more points selected, the longer the processing time will be. After the points have been selected, click on the "RecalcSelected" button found on the toolbar. A message box will be displayed when the recalculation is complete detailing the number of points updated (fig. 12). The colors of the selected pour points will reflect the updated SIP.

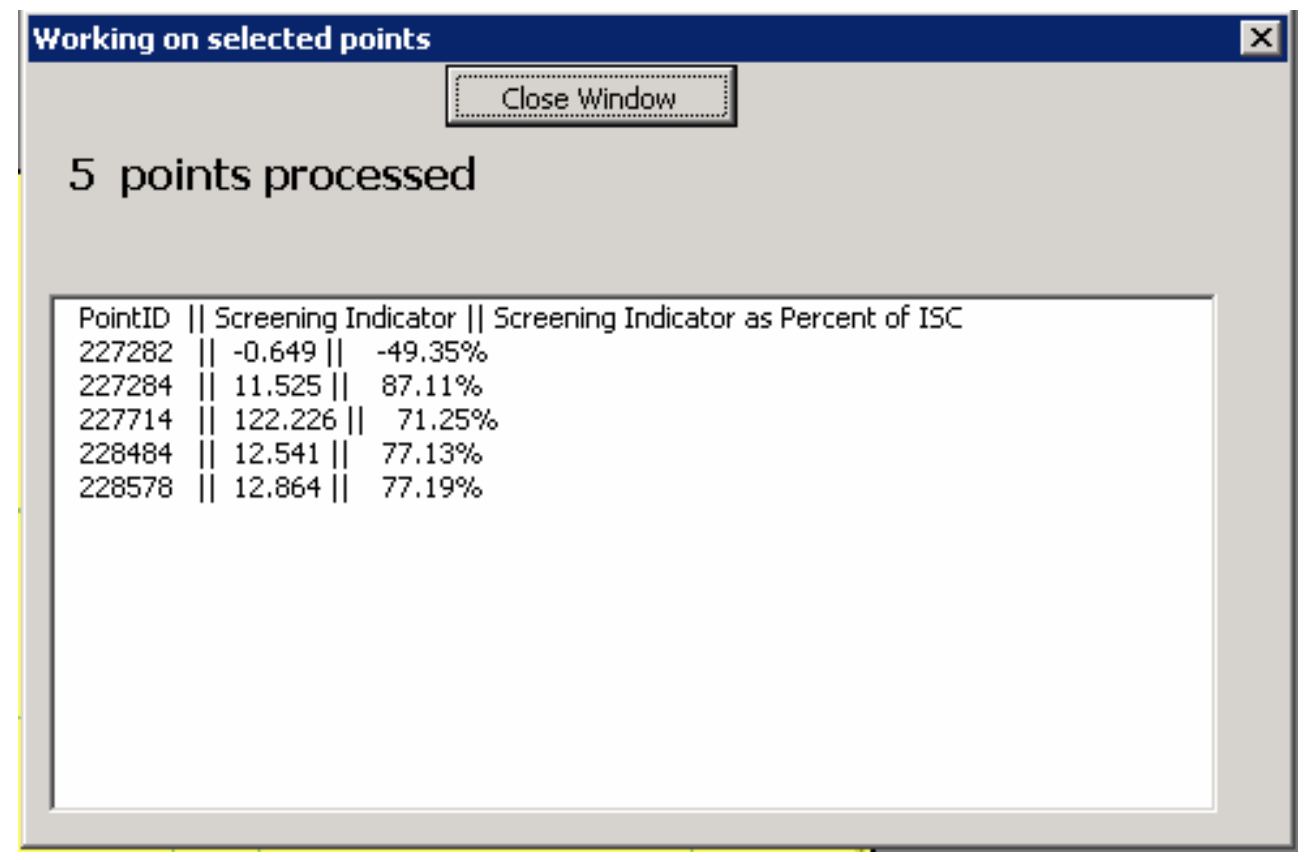

Figure 12. Message box using the RecalcSelected function. 


\section{"SaveNewScenario" Function}

The purpose of this function is to save current edited data values for use at a later date. This may be of use when the user is trying different "what-if" scenarios and would like to save the outcome. To use this function, click on the "SaveNewScenario" button on the toolbar and a form will be displayed asking for the name of the new scenario (fig. 13). After the name has been entered, click the "OK" button. The edited data for pour points will be copied to the Edits database and related by the scenario name and number. A name can be used more than once but is not recommended. An error will occur if the data values have not been edited and are still at baseline values.

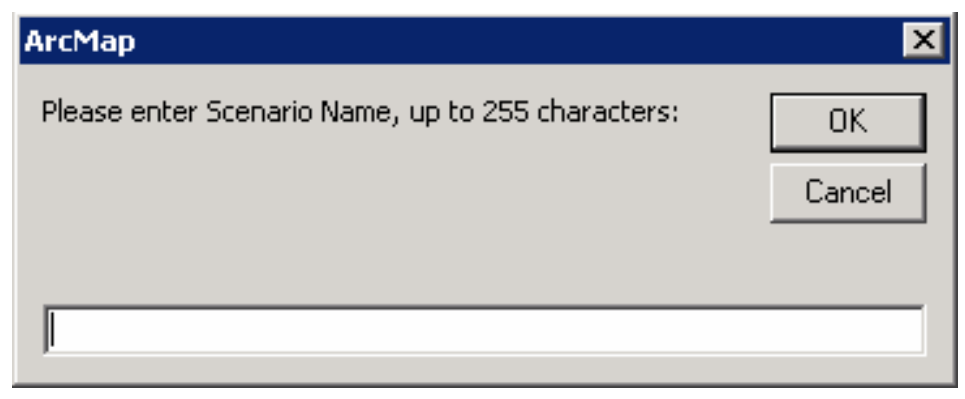

Figure 13. Save new scenario message box.

\section{"RetlSCBaseline" Function}

The purpose of this function is to reset the ISC to the baseline value for all pour points in the database. Using this function replaces the current ISC value with 100 percent of the 7Q10, which is the baseline ISC value. Before using this function, the size of the Basins.mdb should be checked and if approaching maximum size, the database should be compacted. To use this function, click on the "RetISCBaseline" button on the toolbar. When completed, a message box will be displayed (fig. 14).

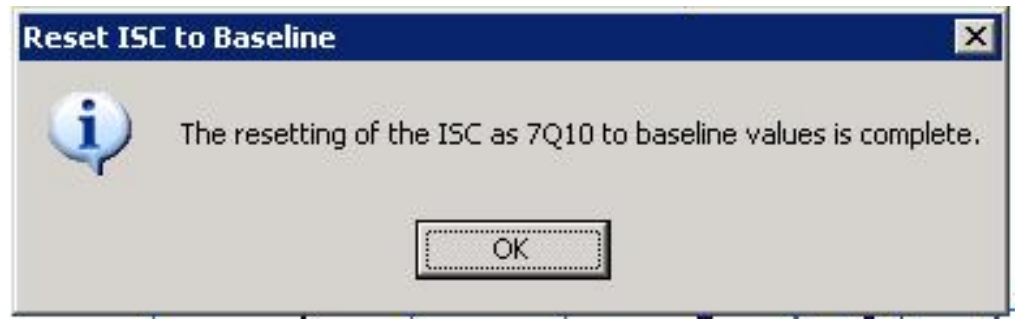

Figure 14. Return initial screening criteria to baseline message box. 


\section{"RetWUBaseline" Function}

The purpose of this function is to reset the water-use withdrawals to the baseline values for all pour points in the database. Using this function replaces the current withdrawal values, both by total and categories, with the original unedited withdrawal values. Withdrawals edited through use of the "EditData" or "RecalcSelected" functions will be returned to baseline. To use this function, click on the "RetWUBaseline" button on the toolbar. A message box is displayed when completed (fig. 15).

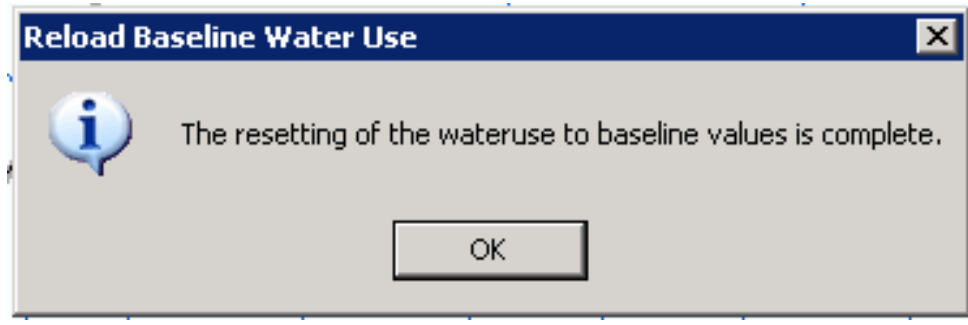

Figure 15. Return water use to baseline message box.

\section{“RetDischBaseline" Function}

The purpose of this function is to reset the water-use discharges to the baseline values for all pour points in the database. Using this function replaces the current discharge values, both by total and categories, with the original unedited discharge values. Discharges edited through use of the "EditData" or "RecalcSelected" functions will be returned to baseline. To use this function, click on the "RetDischBaseline" button on the toolbar. When completed, a message box will be displayed (fig. 16).

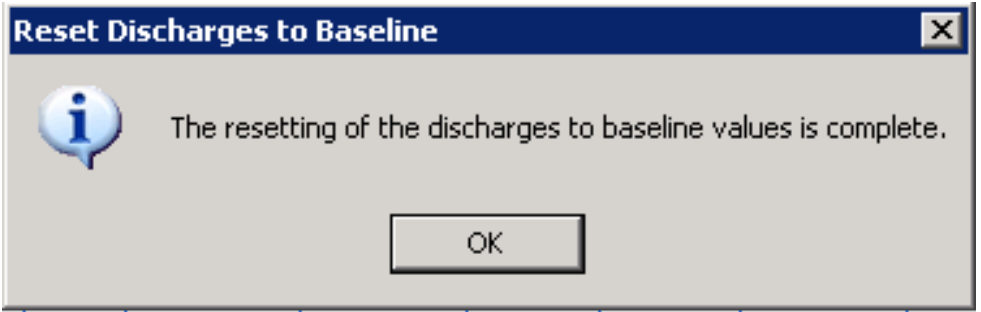

Figure 16. Return discharges to baseline message box. 


\section{“LoadNewWaterUse" Function}

The purpose of the "LoadNewWaterUse" function is to load new water-use information from the working water-use database and recalculate all values, including water-use totals, ratios, SI, and SIP, at each pour point in the state. This allows the user to read in new water-use data as updates or new data become available or as errors are corrected to the water-use database. All previous water-use data will be deleted before new data can be read in. Backing-up previous water-use data or copying WAST and databases into a new directory before using this function is recommended.

Before invoking this function, steps must first be completed outside of the WAST. The steps are outlined in table 1. First, copy Basins.mdb and WaterUsePoints.mdb into a new directory to be stored as back-ups, if not done previously. Second, a new watuse table that contains all necessary fields and formats as described in appendix 3 must be imported into the WaterUse database. To do this, with the WAST closed, open the WaterUsePoints.mdb using Microsoft Access. Delete or rename the existing watuse table; renaming the watuse table will maintain previous data sets. Select File; Get External Data; Import Data to select the new watuse table. Close the database when complete.

The third step that must be done before using the "LoadNewWaterUse" function is to compact the Basins database. As the WAST is run under normal conditions, the size of the Basins.mdb can double. To load new water use into WAST using the "LoadNewWaterUse" function, all possible available space is needed. With all databases and the WAST closed, open ArcCata$\log$ to compact the Basins database. In the Table of Contents, navigate to Basins.mdb. Right-click on Basins.mdb in the Table of Contents and select compact database. It is recommended to use ArcCatalog to compact the database because it contains feature classes. However, if ArcCatalog is unavailable, Microsoft Access may be used to compact the database. The compacted size of Basins.mdb is about 750 kilobytes.

When these steps are completed and before running the "LoadNewWaterUse" function, the fourth step is to open the WAST and return ISC to baseline, either through setting "FractionateISC" to 100 percent or using the "RetISCBaseline" function. This step is crucial to the accuracy resulting from the "LoadNewWaterUse" function. During this function, the baseline data are deleted and the current ISC becomes the new baseline values. If the ISC is not returned to baseline (100 percent) prior to running "LoadNewWaterUse" function, the ISC values and resulting calculations of SI and SIP saved in the tables and displayed in the WAST will be incorrect.

After completing these three steps, the "LoadNewWaterUse" function is ready to be used. Click on the "LoadNewWaterUse" button on the toolbar and a box will be displayed alerting the user that using this function may take a long time. The user selects Yes to continue, and another box will be displayed asking the user to enter a reference date for the new water use (fig. 17). The date must be entered in a MM/DD/YYYY format. If no date is entered, a box will be displayed asking the user to re-enter the date or to use today's date (fig. 18). After a date has been entered, the progress is displayed at the bottom of the WAST screen. For Pennsylvania, this function typically takes 12 or more hours to run for the entire state so running overnight is suggested.

Table 1. Steps required to run "LoadNewWaterUse" function.

[7Q10, 7-day, 10-year low flow is the discharge at the 10-year recurrence interval taken from a frequency curve of annual values of the lowest mean discharge for 7 consecutive days (the 7-day low flow); ISC, initial screening criteria; WAST, water-analysis screening tool]

\begin{tabular}{clc}
\hline Step & \multicolumn{1}{c}{ Description } & Note \\
\hline 1 & $\begin{array}{c}\text { Copy Basins.mdb and WaterUsePoints.mdb into separate } \\
\text { directory as back-up of data } \\
2\end{array}$ & $\begin{array}{c}\text { Import new "watuse" table into WaterUsePoints.mdb } \\
\text { Back-up of data may be needed if all steps are not followed } \\
\text { properly } \\
\text { Code looks for exact name and formatting as found in existing } \\
\text { "watuse" and shown in appendix } 4\end{array}$ \\
3 & Compact Basins.mdb using ArcCatalog & $\begin{array}{c}\text { Compacted size is around 750 kilobytes } \\
\text { Use either "FractionateISC" function or "RetISCBaseline" } \\
\text { function. Current ISC becomes baseline ISC. } \\
\text { With a full dataset, processing time can be substantial }\end{array}$ \\
\hline
\end{tabular}




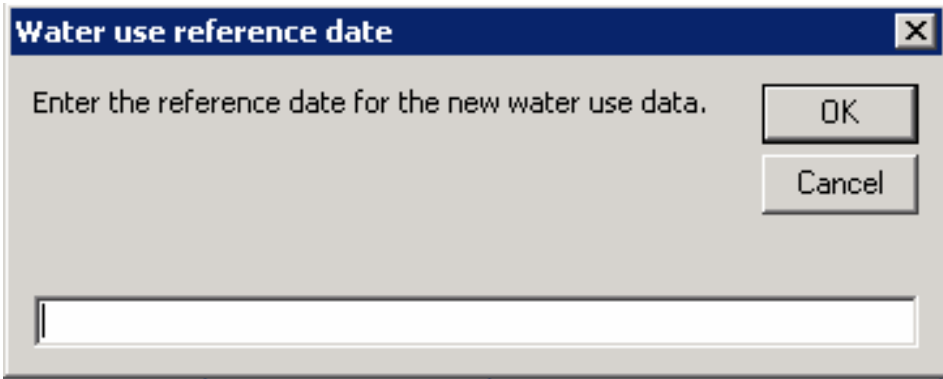

Figure 17. Water-use reference date message box.

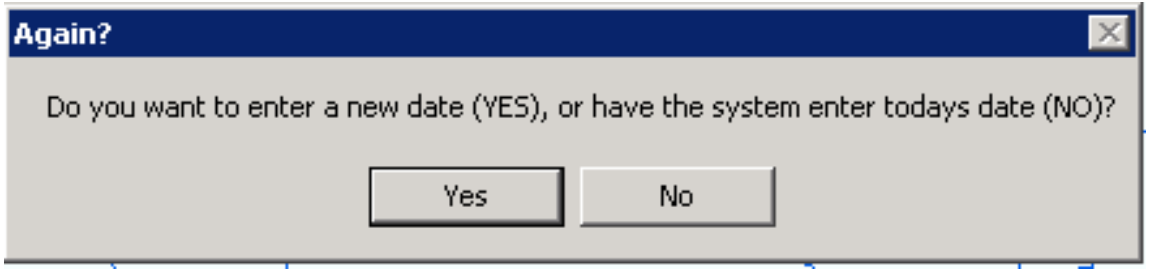

Figure 18. Invalid water-use reference date message box.

\section{“ReloadScenario" Function}

The purpose of this function is to reload the edited data values associated with a selected scenario. A scenario must first be saved using the "SaveScenario" function discussed previously. To use this function, click on the "ReloadScenario" button on the toolbar and a message box will be displayed asking the user to select a scenario (fig. 19). Select the scenario by clicking on the scenario name and then clicking on "Select existing scenario, then click this button" button. The WAST replaces the data values for the pour points associated with the scenario with the values contained in the edits table in Edits.mdb. If pour points other than those associated with the scenario have been edited since the scenario was saved, the edited data values for those pour points are replaced by the values in Edits.mdb or reset to baseline values.

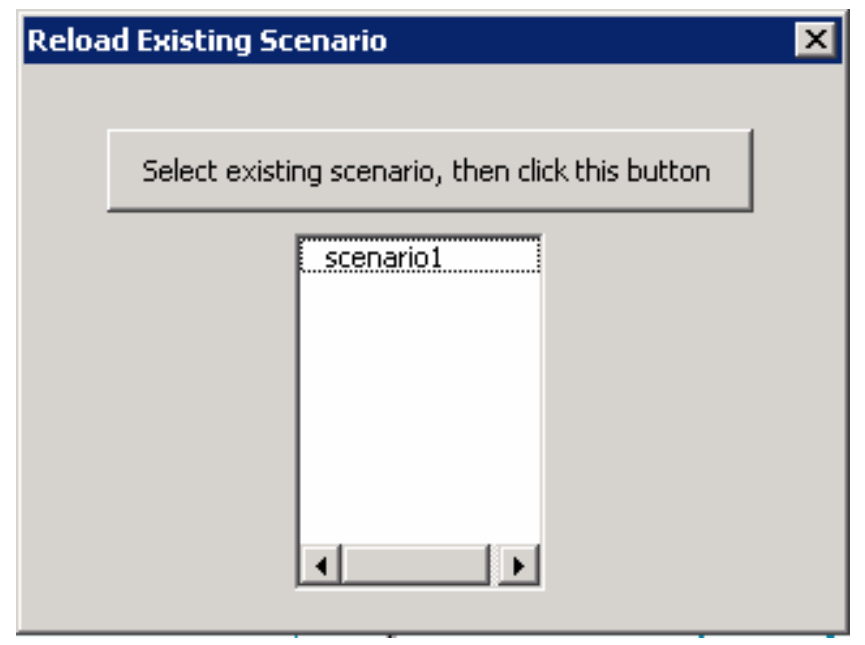

Figure 19. Reload existing scenario message box. 


\section{“ExcelSelected" Function}

The purpose of the "ExcelSelected" function is to save data for selected pour points to a Microsoft Excel spreadsheet. To use this function, first use the ArcGIS feature selection tool ( sheet. The WatershedPoints layer should be the only layer selectable. Hold the "Shift" key down to select multiple points or click and hold down while dragging the box over multiple points. There is no maximum or minimum number of pour points that can be processed. The more points selected, the longer the processing time. After the points have been selected, click on the "ExcelSelected" button. A box will be displayed when processing is complete detailing the number of points exported. The resulting Excel spreadsheet is written to the "My Documents" directory with the name "watUseRptYYYYMMDD-HHMMSS," where YYYYMMDD is the year, month, and day and HHMMSS is the hour, minute, and second the file was created.

The following fields are populated in the Microsoft Excel spreadsheet as part of this function:

Hydro ID is the unique identifier assigned to each point, from the Basins table;

StreamName is the stream name as determined from the NHD, if available;

Drainage Area is the drainage area of the watershed, in square miles;

Screening Indicator is the screening indicator, in million gallons per day;

Screening Indicator as a Percent of Initial Screening Criteria (ISC) is the screening indicator as a percentage;

ISC as $7 Q 10$ is the ISC, in million gallons per day;

Total Discharges is the total discharges in the watershed, in million gallons per day;

Total Withdrawals is the total withdrawals in watershed, in million gallons per day; and

Water Purveyor, Estimated Residential, Industrial, Estimated Industrial, Commercial, Estimated Commercial, Agricultural, Estimated Agriculture, Electric, Mineral, and Discharge from Mines are the total water use by category in the watershed, in million gallons per day.

\section{“Help” Function}

The purpose of this function is to display a help file in Microsoft Notepad. The help file contains general explanations and instructions on how to use the WAST functions. More detailed explanations or instructions regarding the functions are available in this users guide. For more information regarding the methods used to determine the WAST inputs, users should refer to Stuckey (2008). To use the "Help" function, click on the "Help" button on the toolbar and the file will open in Microsoft Notepad.

\section{Limitations of WAST}

The WAST was built using a geodatabase structure that utilizes Microsoft Access. Inherent to Microsoft Access is the size limitation that a database cannot exceed about 2 Megabytes. As the different functions are used in the WAST, the Basins.mdb geodatabase increases in size to approach and occasionally exceed the size limitation. When this occurs, an error message specific to the database size is not displayed; however, a general error message is displayed and the WAST does not function correctly. The user should note the size of the Basins.mdb at the start of each session and compact it using ArcCatalog if the size is over 1.6 Megabytes.

The WAST was developed to provide an initial screening of the potential influence of net withdrawals on aquatic-resource uses. From this initial screening, areas of the state can be identified that have potential conflicts with aquatic-resource uses and further work can be prioritized. Further investigation into the water use, ISC, and mitigation efforts would be needed before a watershed can be designated as a CWPA. The accuracy of the WAST depends on the accuracy of the input data, specifically the water use and the ISC. The data for each watershed should be carefully examined for accuracy.

Other limitations regarding the methodology used to develop the input datasets for the WAST can be found in Stuckey (2008). 


\section{Summary}

The WAST was developed by the USGS, in partnership with PaDEP, to provide assistance in the identification of CWPAs as part of the State Water Plan update. The WAST compares water-use information to the ISC, resulting in a screening indicator for influences of net withdrawals on aquatic-resource uses. The SIP is displayed in the WAST as ranges of colors for points representing the outlets of watersheds. Green is used to indicate areas that have a low potential for aquatic-resource conflicts, white is used to indicate areas that cannot conclusively be labeled as having a high or low potential for conflicts, and yellow is used to indicate areas with a high potential for conflicts with aquatic-resource uses.

The WAST can display general basin characteristics, water-use information, and screening-indicator information for over 10,000 watersheds in the state. Water-use and water-supply information can be edited to refine the inputs for a particular watershed to more closely replicate actual conditions. The WAST includes 12 primary functions, including ShowBaselineData, EditData, FractionISC, RecalcSelected, SaveNewScenario, RetISCBaseline, RetWUBaseline, RetDischBaseline, LoadNewWaterUse, ReloadScenario, ExcelSelected, and Help. These functions allow the user to display watershed information, edit watershed information including water supply (ISC) and water use, observe effects downstream from edited water-use information, reset edited values to baseline, load new water-use information, save and retrieve scenarios, and save output as a Microsoft Excel spreadsheet.

The individual geodatabases used by the WAST have a maximum size limitation of about 2 Megabytes. The user must be aware of the size of the Basins.mdb and compact as necessary. The WAST is also limited by the accuracy and completeness of the input data, specifically the water-use information and the 7Q10 values.

\section{Acknowledgments}

The WAST was originally conceived by William Gast, retired PaDEP Chief of Water-Use Planning, with primary development from Jeffrey Strause, currently a retired hydrologist from the USGS Pennsylvania Water Science Center (PAWSC); many thanks go to Mr. Gast for initiating the concept and to Mr. Strause for his hard work in developing an idea into a functioning screening tool. The authors thank the following employees of the USGS PAWSC: Scott Hoffman, for developing the geographic information system (GIS) data sets for the WAST and providing GIS assistance; and Linda Zarr, for providing database assistance. Thanks also to PaDEP staff, including Michael Hill, Abdolhossain Liaghat, and David Jostenski, who helped develop nay of the functional aspects of the tool and who provided assistance and testing of the tool throughout its development.

\section{References Cited}

ESRI, 2007, What's new in ArcGIS 9.2: ESRI White Paper, 250 p., accessed February 13, 2008, at http://support.esri.com/ index.cfm? $f a=$ knowledgebase. whitepapers. viewPaper $\& P I D=43 \&$ MetaID $=1256$

Pennsylvania Department of Environmental Protection, 2006, Guidelines for identification of critical water planning areas: Document 392-2130-014, 17 p.

Pennsylvania Fish and Boat Commission, 2007, 2007 Class A wild trout waters: Commonwealth of Pennsylvania, accessed August 22, 2007, at http://www.fish.state.pa.us/classa98.htm

Stuckey, M.H., 2006, Low-flow, base-flow, and mean-flow regression equations for Pennsylvania streams: U.S. Geological Survey Scientific Investigations Report 2006-5130, 84 p.

Stuckey, M.H., 2008, Development of the Water-Analysis Screening Tool used in the initial screening for the Pennsylvania State Water Plan Update of 2008: U.S. Geological Survey Open-File Report 2008-1106, 9 p.

U.S. Geological Survey, 2004, The National Hydrography Dataset NHD watershed tool-Instructions for preprocessing supporting data layers: accessed April 1, 2008, at http://nhd.usgs.gov/watershed/watershed_tool_inst_TOC.html\#Toc474479740 


\section{Appendixes}

Appendix 1. Water-Analysis Screening Tool Code

Appendix 2. Reference Libraries Needed to Run the Water-Analysis Screening Tool

Appendix 3. Data Dictionaries for the Water-Analysis Screening Tool Databases

Appendix 4. Example Databases and Executable Code

Appendix 5. Guidelines for Resolving Problems Encountered While Running the Water-Analysis Screening Tool 

옹

옥

恿 